\title{
C-Type Natriuretic Peptide Specifically Acts on the Pylorus and Large Intestine in Mouse Gastrointestinal Tract
}

\author{
Chizuru Sogawa, ${ }^{*}$ Hidekatsu Wakizaka, ${ }^{\dagger}$ Winn Aung, ${ }^{*}$ Zhao-hui Jin, ${ }^{*}$ Atsushi B. Tsuji, ${ }^{*}$ Takako Furukawa, ${ }^{*}$ Tetsuo Kunieda, ${ }^{\ddagger}$ \\ and Tsuneo Saga*
}

From the Diagnostic Imaging* and Biophysics ${ }^{\dagger}$ programs, Molecular Imaging Center, National Institute of Radiological Sciences, Chiba; and the Department of Animal Genetics ${ }^{\ddagger}$ Graduate School of Natural Science and Technology, Okayama University, Okayama, Japan

\author{
Accepted for publication \\ September 13, 2012. \\ Address correspondence to \\ Chizuru Sogawa, M.Sc., \\ Diagnostic Imaging Group, \\ Molecular Imaging Center, \\ National Institute of \\ Radiological Science, 4-9-1 \\ Anagawa, Inage-ku, Chiba \\ 263-8555, Japan. \\ E-mail: c-sogawa@nirs.go.jp.
}

\begin{abstract}
C-type natriuretic peptide (CNP) exerts its main biological effects by binding to natriuretic peptide receptor B (NPR-B), a membrane-bound guanylyl cyclase receptor that produces cyclic guanosine monophosphate (cGMP). CNP is known to cause gastrointestinal (GI) smooth muscle relaxation. Experimental evidence suggests a connection between CNP signaling and GI function, with reactive regions in the GI tract possibly affecting transit; however, this relation has not yet been conclusively shown. Here, we show that CNP plays important region-specific roles in the GI tract of mice. We found that treatment with CNP (1 or $2 \mathrm{mg} / \mathrm{kg}$ ) increased transient cGMP production in the pylorus, colon, and rectum, with the higher dose $(2 \mathrm{mg} / \mathrm{kg}$ ) enhancing gastric emptying in mice; this increase in cGMP levels was however absent in NPR-B-deficient short-limbed dwarfism (SLW) mouse. Furthermore, we found that NPR-B is highly expressed in the pylorus, colon, and rectum, being localized to nerve fibers and to the nuclei and cytoplasm of smooth muscle cells of the GI tract and blood vessels. Our in vivo findings showed that NPR-B-mediated CGMP production after CNP administration specifically acted on the pylorus, colon, and rectum and contributed to gastric emptying. CNP may thus be a potential therapeutic agent for GI motility/transit disorders such as ileus and pyloric stenosis. (Am J Pathol 2013, 182: 172-179; http://dx.doi.org/10.1016/j.ajpath.2012.09.015)
\end{abstract}

The natriuretic peptide family comprises atrial natriuretic peptide (ANP), ${ }^{1}$ brain natriuretic peptide $(\mathrm{BNP}){ }^{2}$ and C-type natriuretic peptide $(\mathrm{CNP}) .^{3}$ The following three natriuretic peptide receptors are known: type A (NPR-A), type B (NPR-B), and type C (NPR-C). NPR-A and NPR-B consist of extracellular ligand-binding domains, intercellular transmembrane domains, protein kinase homology domains, and the guanylyl cyclase domain; these receptors mediate ligand signals produced by intracellular cyclic guanosine monophosphate (cGMP), which acts as a secondary messenger ${ }^{4}$ and is degraded by cGMP-specific phosphodiesterase type $5 .^{5}$ NPR-A preferentially binds ANP and BNP. NPR-B has a considerably higher affinity for CNP than for ANP or BNP. ${ }^{6-8}$ NPR-C is devoid of intercellular domains; it is believed to be a clearance receptor. ${ }^{6-8}$

ANP and BNP are circulating peptides that are synthesized mainly in the atrium and the ventricle of the heart, respectively. ${ }^{9} \mathrm{CNP}$ is present mainly in the vascular endothelium and exhibits different local autocrine and paracrine functions, both within and outside the cardiovascular system, ${ }^{10,11}$ and these functions are involved in regulating vascular smooth muscles. ${ }^{12}$ It was considered that CNP signaling similarly affects the gastrointestinal (GI) smooth muscles, and this was experimentally proven in several animal species. ${ }^{13-16}$ Therefore, NPR-B-mediated cGMP production stimulated by $\mathrm{CNP}$ is believed to play an important role in regulating the GI tract.

We recently reported that the short-limbed dwarfism (SLW) mouse $^{17}$ has a mutation in Npr-2, the gene encoding NPR-B, which results in deletion of the intracellular domain of NPRB. ${ }^{18}$ We also showed that homozygous $(s l w / s l w)$ mice have abnormal retention of gastric milk and distention of the intestinal tract with gas, because of the lack of a CNPmediated relaxation response in the pylorus and large intestine, and die before weaning. ${ }^{18}$ The $s l w / s l w$ mutant mouse thus exhibits a GI abnormality that resembles pyloric stenosis or ileus. These findings suggested that the GI tract might have

Supported by the Diagnostic Imaging Group, Molecular Imaging Center, National Institute of Radiological Sciences, Japan. 
a specific CNP signaling reactive region that affects intestinal transit. Despite the evidence to support an association between CNP and GI tract function, no such CNP-specific reactive region has been found. Moreover, the relation between CNP signaling and GI transit has not yet been conclusively shown. Therefore, the present study aimed to elucidate the presence of such CNP-specific reactive regions and to clarify the relation between CNP signaling and GI transit.

\section{Materials and Methods}

Mice

Four-week-old female ddY mice were obtained from Japan SLC, Inc. (Shizuoka, Japan) and maintained for 1 week under standard conditions with a 12-hour light/dark cycle (light: 7:00 AM to 7:00 PM) before experiments. All experiments were performed with identical age-matched 5-week-old mice that were sacrificed at approximately the same time (between 8:00 AM and 10:00 AM). SLW mice, with an NPR-B disturbance caused by a mutation in the Npr-2 gene, representing an inbred strain maintained under standard conditions and only once backcrossed to the ddY mouse, were mated with heterozygous mice. The experimental protocol was approved by the Institutional Animal Care and Use Committee of the National Institute of Radiological Sciences, and all animal experiments were performed in accordance with institutional guidelines for animal care and handling.

\section{Measurement of cGMP}

Mice were separated into four groups: the untreated (baseline) group, the $2-\mathrm{mg} / \mathrm{kg} \mathrm{CNP}$ group, the $1-\mathrm{mg} / \mathrm{kg} \mathrm{CNP}$ group, and the vehicle (normal saline) group. CNP-22 (4229-v; Peptide Institute, Osaka, Japan) and vehicle were administered intravenously.

cGMP levels were measured with a cGMP Enzymeimmunoassay Biotrak System (RPN226; GE Healthcare, Little Chalfont, United Kingdom). Purification of cGMP from GI tissue samples was performed according to the manufacturer's instructions as protocol 2. Briefly, a GI tissue sample was taken, and the contents were removed with forceps (the sample was not washed). The tissue was weighed, immersed in $1 \mathrm{~mL}$ of $65 \%$ ice-cold ethanol, and minced. The tissue was allowed to settle for 10 to 15 minutes and then centrifuged at $2000 \times g$ for 15 minutes at $4^{\circ} \mathrm{C}$. The supernatant fluid was transferred to a new tube and then dried at $60^{\circ} \mathrm{C}$ with the use of a vacuum evaporator. The sample was rehydrated by adding $50 \mu \mathrm{L}$ of enzyme immunoassay dilution buffer per $10 \mathrm{mg}$ of tissue.

\section{Western Blot Analysis}

Western blot analysis was performed to analyze proteins in the mouse tissue samples. GI tissue samples were homogenized with protein lysis reagent (CelLytic MT;

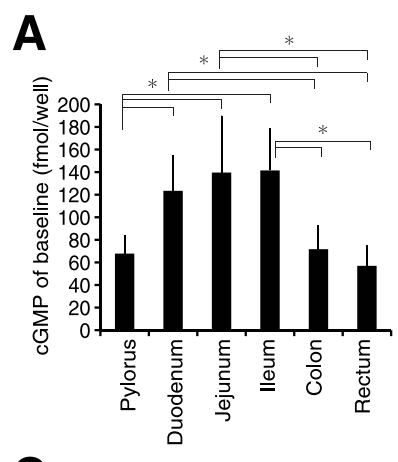

B
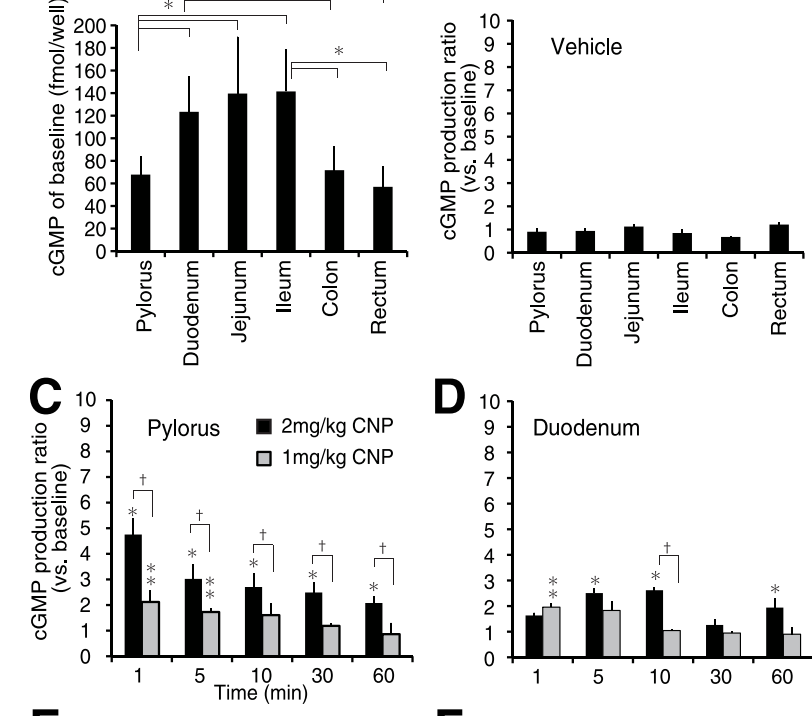

D
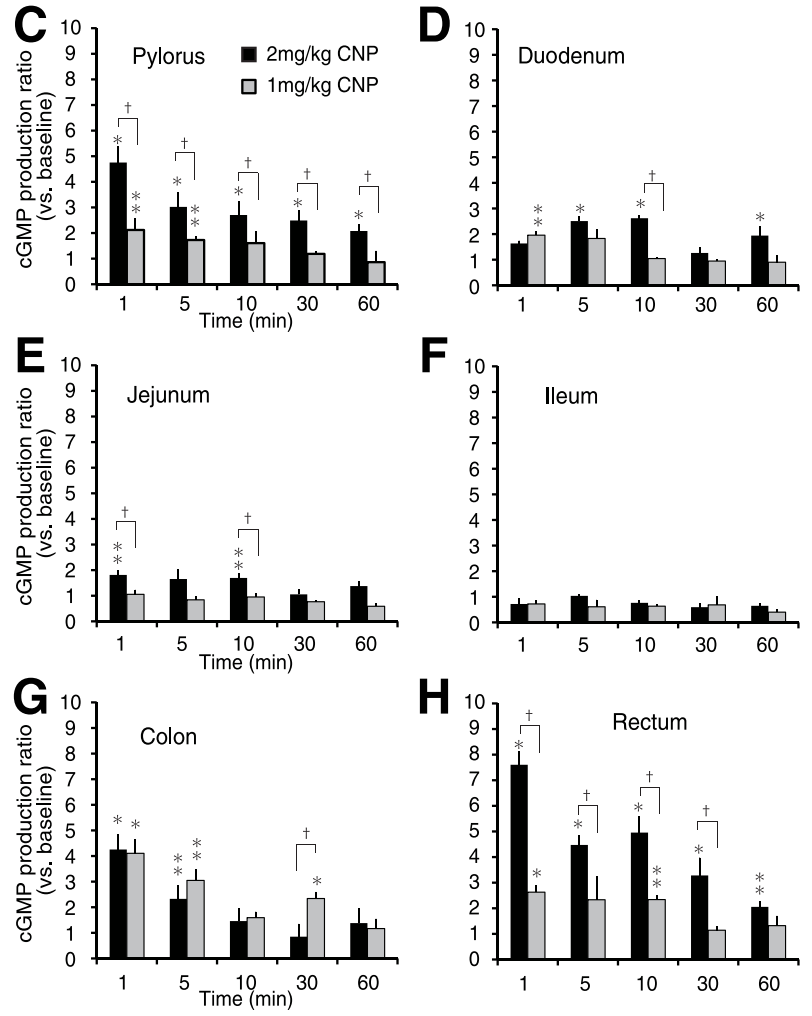

$$
\text { I }
$$

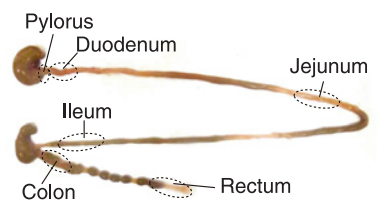

Figure 1 Comparison of CGMP production. A: Comparison of the baseline cGMP levels in the GI tract. The data shown represent the means (columns) and SDs $(n=4)$. ${ }^{*} P<0.05$. B: cGMP production ratio at 1 minute after vehicle administration versus baseline. The data shown are the means (columns) and SDs ( $n=4$ to 8$)$. $\mathbf{C}-\mathbf{H}$ : Time course of cGMP production in pylorus (C), duodenum (D), jejunum (E), ileum (F), colon (G), and rectum (H). The data shown are the means (columns) and SDs, and the black and gray columns indicate the $2-\mathrm{mg} / \mathrm{kg}$ CNP-induced cGMP levels and $1-\mathrm{mg} / \mathrm{kg} \mathrm{CNP}$ induced cGMP levels, respectively ( $n=4$ to 8 for each group of mice). ${ }^{*} P<0.001,{ }^{* *} P<0.01$ versus baseline; ${ }^{\dagger} P<0.01,2-\mathrm{mg} / \mathrm{kg}$ CNP-induced cGMP levels versus $1-\mathrm{mg} / \mathrm{kg}$ CNP-induced cGMP levels. I: The sampling regions used in each experiment for the measurement of cGMP production.

Sigma-Aldrich, St. Louis, MO) and protease inhibitor cocktail (P8340; Sigma-Aldrich) according to the manufacturer's instructions. Total protein was separated on a $10 \%$ polyacrylamide gel (e.PAGEL; ATTO Corporation, Tokyo, 
Japan) and then transferred to a polyvinylidene difluoride membrane (Millipore, Billerica, MA) with the use of an iBlot Gel Transfer Device (IB1001 and IB4010-02; Invitrogen, Carlsbad, CA). The membrane was blocked with Block-Ace (Dainippon Pharmaceutical, Osaka, Japan) for 1 hour at room temperature and then incubated with the primary antibodies, a rabbit polyclonal anti-human NPR2 (N-terminus) antibody (LS-C-101220; LifeSpan BioScience, Inc., Seattle, WA; 1:100 dilution) for NPR-B and a goat anti-human actin antibody (C-11; Santa Cruz Biotechnology, Santa Cruz, CA; 1:200 dilution), for 1 hour at room temperature. After incubation, the membrane was washed three times with Tris-buffered saline (TBS) containing $0.05 \%$ Tween 20 and then incubated with the appropriate horseradish peroxidase (HRP)-linked secondary antibody, donkey anti-rabbit IgG (GE Healthcare; 1:2000 dilution) for NPR-B and donkey anti-goat IgG (SC-2020; Santa Cruz Biotechnology; 1:4000 dilution) for actin. Immunoreactive bands were visualized with Luminata Forte Western HRP Substrate (WBLUF0100; Millipore). Membranes were stripped and reprobed with each antibody to detect NPR-B and actin on the same membrane.

\section{Immunohistochemistry}

The localization and distribution of NPR-B in smooth muscle, nerves, and vessels was investigated by immunohistochemistry. The GI tract was prepared from the stomach to anus, fixed in Bouin solution for 4 hours at room temperature, and then immersed in $70 \%$ ethanol for 48 hours. The specimens were dehydrated and embedded in paraffin. Subsequently, $2-\mu \mathrm{m}-$ thick sections were cut, attached to glass slides (MAS-GP Type A; Matsunami Glass Ind., Ltd., Osaka, Japan), and then deparaffinized and rehydrated. For antigen retrieval, sections were incubated in $10 \mathrm{mmol} / \mathrm{L}$ sodium citrate $(\mathrm{pH} 6)$ that contained $0.05 \%$ Tween- 20 for 10 minutes at $95^{\circ} \mathrm{C}$, and then cooled to room temperature. The sections were washed in distilled water, immersed in TBS (S3001; Dako Japan, Tokyo, Japan), and then incubated in peroxidase-blocking solution (3\% $\mathrm{H}_{2} \mathrm{O}_{2}$ in methanol) for 10 minutes at room temperature. Each section was washed three times in TBS for 5 minutes at room temperature, incubated with a nonspecific blocking reagent (X0909; Dako Japan) for 10 minutes at room temperature, and then reacted with the primary antibody for 1 hour at room temperature. Four different primary antibodies were used: rabbit polyclonal antibody for the anti-NPR-B carboxyterminal end (ab37620; Abcam KK, Tokyo, Japan; 1:50 dilution); goat polyclonal anti-SM22- $\alpha$, a smooth muscle marker (ab10135; Abcam KK; 1:70 dilution); mouse monoclonal anti-S100, a Schwann cell marker (ab14849; Abcam KK; 1:1000 dilution); and a monoclonal rat antibody to mouse CD34 (MEC14.7), a small vessel endothelial cell marker (HM1015; Hycult Biotech, Uden, Netherlands; 1:50 dilution), and $\operatorname{IgG}$ from rabbit serum (I5006,
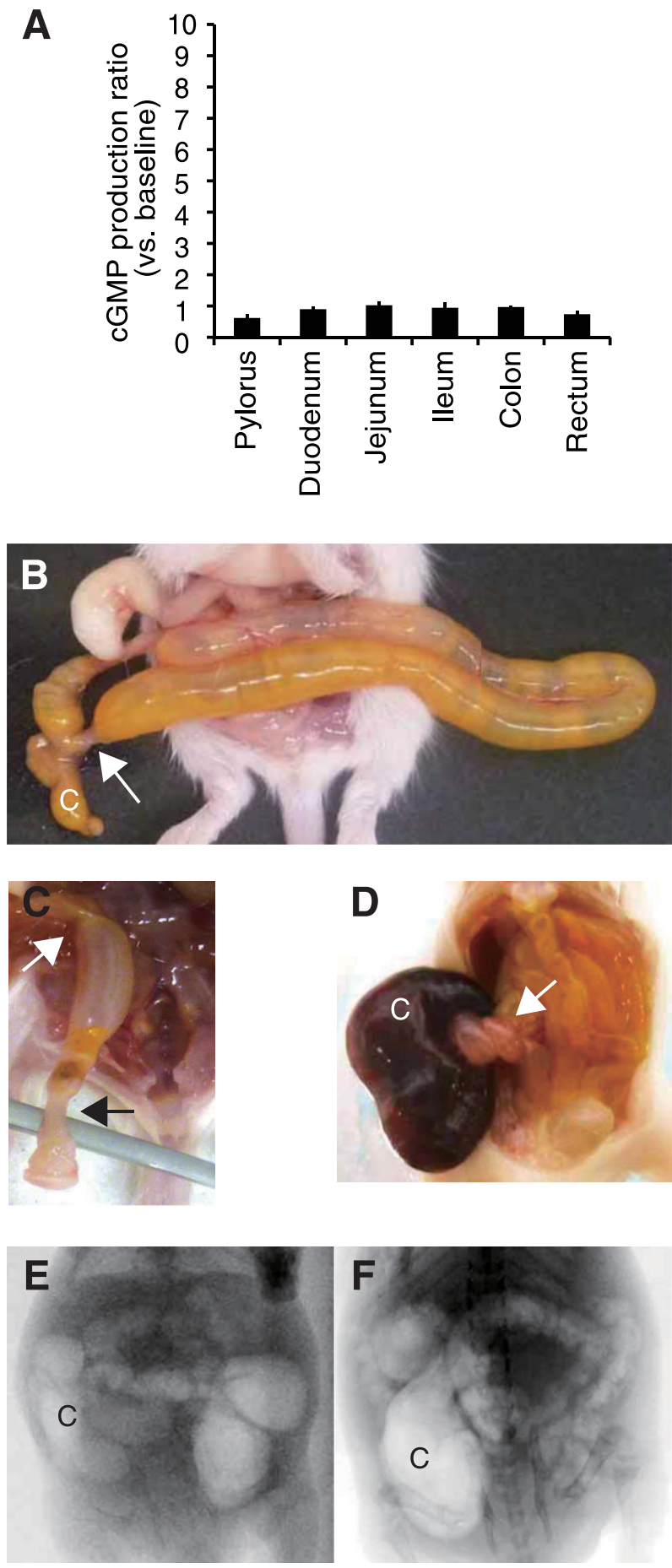

Figure 2 CNP-induced cGMP production and intestinal abnormality of slw/slw mice. A: cGMP production ratio at 1 minute after $2 \mathrm{mg} / \mathrm{kg}$ CNP was administered versus baseline. The data shown are the means (columns) and SDs (bars) ( $n=3$; 3-week-old postnatal $s l w / s l w$ mice). B: The phenotype of 14-day postnatal $s / w / s l w$ mouse, indicating ileus in the ileocecal region (arrows). C: The phenotype of 14-day postnatal slw/ slw mouse, indicating ileus in the rectal region (black and white arrows). Upstream of ileus showed intestines distended and filled with gas. D: The phenotype of 12-day postnatal $s / w / s / w$ mouse, indicating volvulus in the ileocecal region (arrows). The volvulus produced congestion in the cecum. E and F: Radioscopic images of 12-day postnatal $s / w / s l w$ mouse. The GI tract showed an abnormal structure due to distension and was filled with gas. $\mathrm{C}$ indicates cecum. 
Sigma-Aldrich; $10 \mu \mathrm{g} / \mathrm{mL}$ dilution) as negative control for NPR-B. After incubation with the primary antibody, each section was washed three times in TBS for 5 minutes at room temperature and then incubated with the secondary antibody for 30 minutes at room temperature. The secondary antibodies used were as follows: ENVISION $^{+}$ rabbit HRP (K400211; Dako Japan) for NPR-B and rabbit serum IgG, donkey anti-goat IgG HRP (SC-2020; Santa Cruz Biotechnology; 1:500 dilution) for SM-22 $\alpha$, ENVISION $^{+}$mouse HRP (K4000; Dako Japan) for S100, and polyclonal rabbit anti-rat immunoglobulins/biotinylated (E0468; Dako Japan; 1:200 dilution) for CD34. Each section was washed three times in TBS for 5 minutes at room temperature. For CD34, sections were incubated with LSAB2 Streptavidin HRP (K1016; Dako Japan) for 10 minutes at room temperature and then washed in TBS. These sections were stained with diaminobenzidine (K346811; Dako Japan) for approximately 2 minutes at room temperature and then washed with distilled water. The nuclei were stained with hematoxylin.

\section{GI Transit}

The effect of CNP on GI transit was investigated with

${ }^{111}$ In-DTPA (Nihon Medi-Physics, Tokyo, Japan). Mice were separated into two groups, a group treated with vehicle and a group treated with $2 \mathrm{mg} / \mathrm{kg} \mathrm{CNP} .{ }^{111} \mathrm{In}-\mathrm{DTPA}(37 \mathrm{kBq})$ was administered orally (pipette on tongue) in a final volume of $20 \mu \mathrm{L}$ in distilled water with $30 \%$ sucrose, and then the vehicle or CNP was injected intravenously. Mice were subsequently sacrificed, each region was sampled, and then radioactivity was measured with an autowell gamma counter (ALOKA, Tokyo, Japan).

\section{Autoradiography}

${ }^{111}$ In-DTPA (185 kBq) was administered orally in a final volume of $20 \mu \mathrm{L}$ in distilled water with $30 \%$ sucrose. After the vehicle or CNP was administered, the mice were sacrificed at various times. The stomach to anus was placed on an imaging plate and exposed for 10 minutes, and images
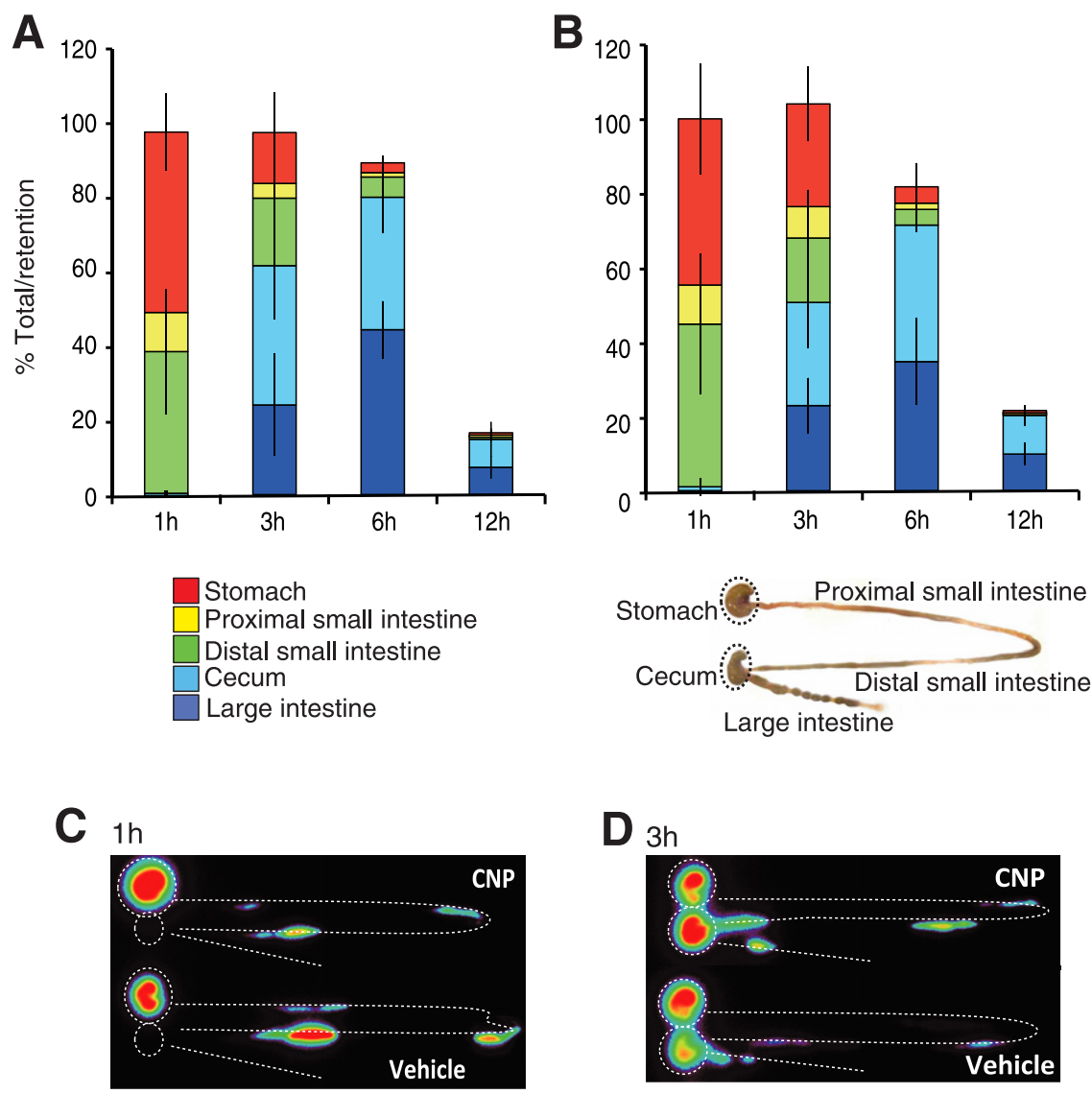

E

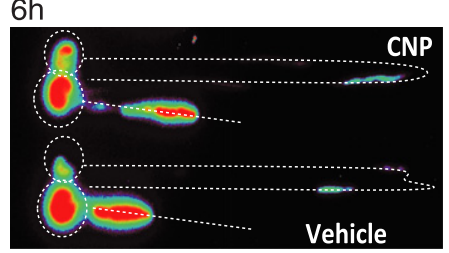

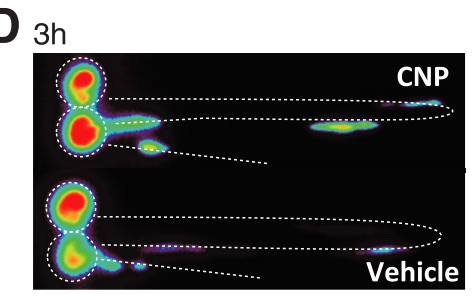

$\mathbf{F}_{12 h}$

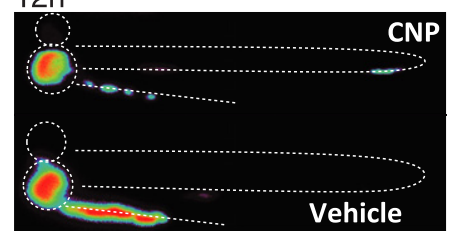

Figure 3 Temporal changes in radioactivity transit in the GI tract after $2 \mathrm{mg} / \mathrm{kg}$ CNP or vehicle was administered. A and $\mathbf{B}$ : Temporal changes in radioactivity retention were measured at $1,3,6$, and 12 hours after $37 \mathrm{kBq}{ }^{111}$ In-DTPA was orally administered to mice treated with $2 \mathrm{mg} / \mathrm{kg}$ CNP (A) and mice treated with vehicle (B). Fractional residual radioactivity (\%) was measured in the stomach, proximal small intestine, distal small intestine, cecum, and large intestine ( $n=4$ to 6$)$. C, D, E, and F: Autoradiography of the GI tract from the stomach (inside the circles on the top left) to the anus (on the bottom right) at 1 hour (C), 3 hours (D), 6 hours (E), and 12 hours (F) after $185 \mathrm{kBq}{ }^{111}$ In-DTPA was orally administered. 
were obtained with an FLA-7000 imager (Fuji Film, Tokyo, Japan).

\section{In Vivo Imaging}

Radioscopic images were obtained to investigate the effect of CNP on the GI motility of normal mice in vivo. Freefeeding and free-drinking mice were fed barium sulfate [2 $\mathrm{g}$ of barium sulfate (Wako Pure Chemical Industries, Osaka, Japan) mixed with $10 \mathrm{~g}$ of $30 \%$ sucrose and $1 \%$ agar]. Mice were anesthetized by isoflurane inhalation, and then the injection route was secured from the tail vein for a dynamic scan with the vehicle or $2 \mathrm{mg} / \mathrm{kg}$ CNP. Images were obtained from a time point before administration to approximately 5 minutes after administration with the use of a microcomputed tomography system (R_mCT2; Rigaku Corporation, Tokyo, Japan).

\section{Statistical Analysis}

Data are expressed as the means \pm SDs. The statistical significance of differences in mean values was assessed by Student's $t$-test.

\section{Results}

\section{Comparison of cGMP Production in the GI Tract of Normal Mice and NPR-B-Deficient Mice}

The GI regions responsive to CNP as evidenced by cGMP production were examined. The cGMP levels in six regions of the GI tract (ie, the pylorus, duodenum, jejunum, ileum, colon, and rectum) were measured after CNP (1 or $2 \mathrm{mg} / \mathrm{kg}$ ) or the vehicle was administered. The cGMP of baseline levels in the small intestine (duodenum, jejunum, and ileum) were higher than that in the pylorus, colon, and rectum (Figure 1A). Administering the vehicle did not affect the cGMP levels in any of the regions (Figure 1B). After $2 \mathrm{mg} / \mathrm{kg}$ CNP was administered, cGMP levels were increased compared with the baseline values in all of the GI regions except the ileum (Figure 1, C-H). In the pylorus and rectum, after $2 \mathrm{mg} / \mathrm{kg}$ CNP was administered, cGMP production was remarkably increased as early as 1 minute compared with that after $1 \mathrm{mg} / \mathrm{kg} \mathrm{CNP}$ was administered (Figure 1, C and H). Particularly, at 1 minute after $2 \mathrm{mg} / \mathrm{kg}$ CNP was administered, cGMP production in the rectum was increased. In the colon, after CNP was administered, cGMP production was increased as early as 1 minute to similar levels for both 1 and $2 \mathrm{mg} / \mathrm{kg}$ CNP (Figure 1G). However, cGMP levels in the duodenum and jejunum were only mildly elevated after CNP administration; furthermore, the cGMP production was only slightly higher after the administration of $2 \mathrm{mg} / \mathrm{kg}$ CNP than that after $1 \mathrm{mg} / \mathrm{kg}$ CNP (Figure 1, D and E). In the ileum, cGMP levels were not increased by CNP administration (Figure 1F).
We also measured the levels of cGMP production in NPR-B-deficient SLW mice to prove whether the CNP effect on the GI tract was specific to NPR-B. None of the GI regions of the $s l w / s l w$ mice showed any increase in cGMP production (Figure 2A). Moreover, the $s l w / s l w$ mice showed not only milk retention in the stomach with distension of the intestinal tract but also the presence of volvulus and ileus in the ileocecal area and the rectum (Figure 2, B-F).
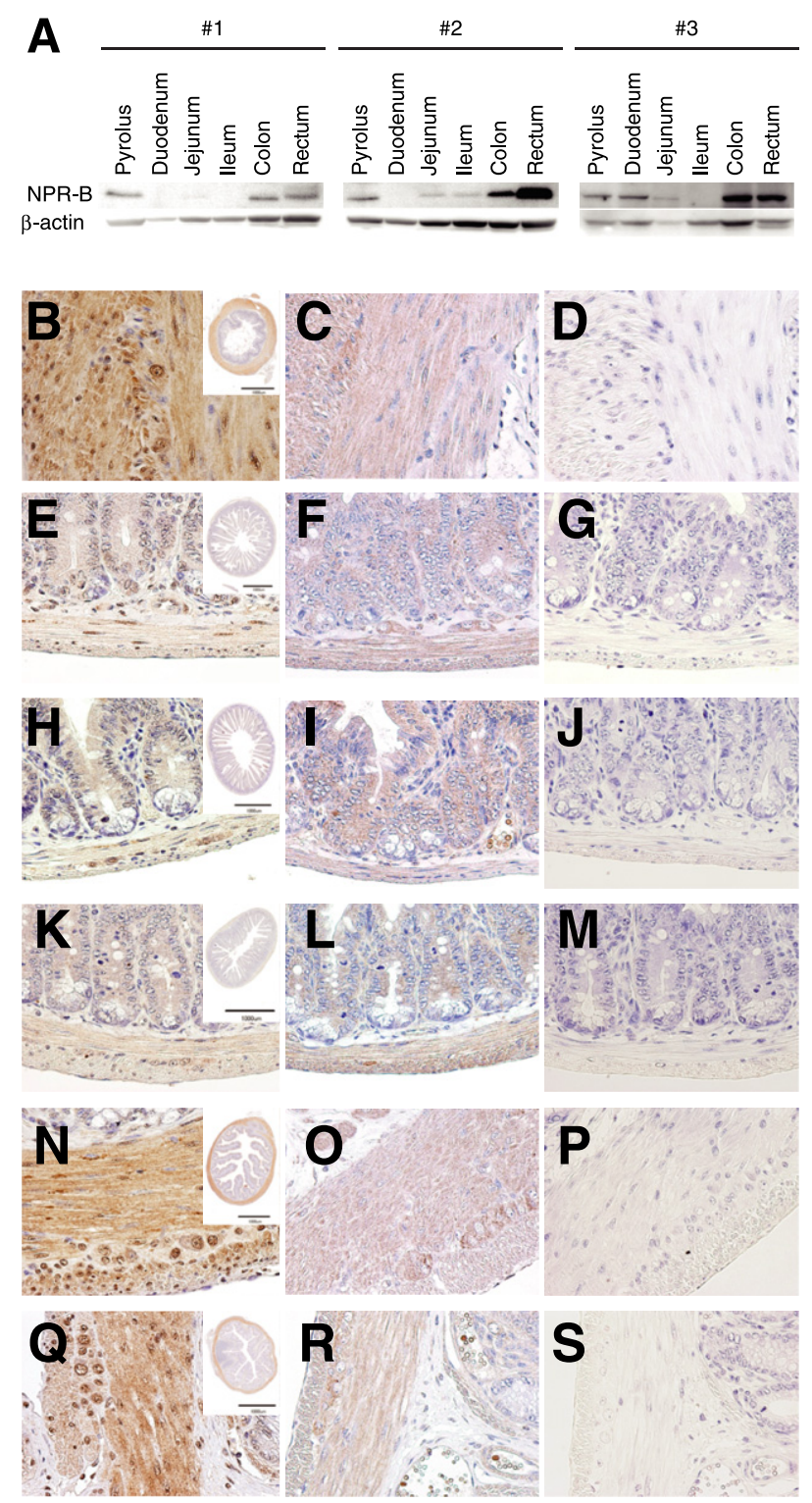

Figure 4 Difference in NPR-B expression. A: Western blot analysis of NPR-B expression in the pylorus, duodenum, jejunum, ileum, colon, and rectum from 3 mice $(\# 1, \# 2$, and $\# 3)$. $\beta$-Actin was used as a loading control. $\mathbf{B}, \mathbf{E}, \mathbf{H}, \mathbf{K}, \mathbf{N}$, and $\mathbf{Q}$ : Results of immunostaining of NPR-B in the pylorus (B), duodenum (E), jejunum (H), ileum (K), colon (N), and rectum (Q) of normal condition mice. The insets show the whole axial image of the magnified image. Scale bars: $1000 \mu \mathrm{m}(\mathbf{B}, \mathbf{E}, \mathbf{H}, \mathbf{K}, \mathbf{N}$, and Q). Negative control using IgG from rabbit serum (C, F, I, L, $\mathbf{0}$, and $\mathbf{R}$ ) and only secondary antibody $(\mathbf{D}, \mathbf{G}, \mathbf{J}, \mathbf{M}, \mathbf{P}$, and $\mathbf{S})$. Original magnification, object lens $\times 40(\mathbf{B}-\mathbf{S})$. 
Visualizing GI Motility for Examining the in Vivo Effect of CNP

We next performed radioscopic studies to investigate the in vivo effect of transient CNP-induced cGMP elevation on GI motility. Before CNP administration, intestinal motility was observed. Immediately after $2 \mathrm{mg} / \mathrm{kg} \mathrm{CNP}$ was administered, motility of the small intestine stopped for approximately 2 to 5 minutes; it was then reactivated. The cecum to colon region was reactivated approximately 3 to 10 minutes after administration (Supplemental Movies S1 and S2). The time elapsing before reactivation showed individual variability, and the small intestine was reactivated earlier than the cecum to colon region in all mice $(n=20)$.

\section{CNP Effect on GI Transit}

Temporal changes in transit of ${ }^{111}$ In-DTPA mixed contents were observed at $1,3,6$, and 12 hours after administration. At 1 hour, the mice treated with $2 \mathrm{mg} / \mathrm{kg} \mathrm{CNP}$ and vehicle exhibited a similar pattern of radioactive retention (Figure 3, A-C). At 3 hours, the $2-\mathrm{mg} / \mathrm{kg} \mathrm{CNP}$ group showed faster gastric emptying and passage to the cecum than the vehicle group (Figure 3, A, B, and D). At 6 hours, all of the groups exhibited prominent radioactivity in the cecum or large intestine (Figure 3, A, B, and E). By 12 hours, almost all radioactivity had passed out of the GI tract in both groups (Figure 3, A, B, and F). At 24 hours, in all groups, nearly all of the radioactive content had passed out of the GI tract (data not shown).

\section{Expression and Localization of NPR-B}

Immunostaining of NPR-B was obviously stronger in the pylorus and large intestine than in the small intestine (Figure 4, B, E, H, K, N, and Q). Rabbit-IgG was used as negative control, but it was not detected in nerve fiber and nuclei of smooth muscle cells (Figure 4, C, F, I, L, O, and R), and staining only secondary antibody did not show positive signaling (Figure 4, D, G, J, M, P, and S). NPR-B localized to nerve fibers and to the nuclei and cytoplasm (Figures 4 , $\mathrm{B}, \mathrm{E}, \mathrm{H}, \mathrm{K}, \mathrm{N}$, and $\mathrm{Q}$, and 5, A, E, and I), it was colocalized to the SM-22 positive cells which include longitudinal muscles, circular muscles, muscularis mucosae, and blood vessel smooth muscle cells (Figure 5, B, F, and J); however, it was not detected in Schwann cells (Figure 5, C, G, and K) or endothelial cells (Figure 5, D, H, and L).

\section{Discussion}

This is a novel report showing the specific action sites of CNP in GI regions in vivo. Importantly, our present results provided evidence to support the presence of region-specific CNP signaling in the pylorus and large intestine of the GI tract; moreover, CNP was shown to contribute to gastric emptying in mice. Although the proximal small intestine was also stimulated by CNP, the changes in cGMP levels were not significant; therefore, CNP was considered to have little effect on proximal small intestinal motility, and CNP signaling may have little effect directly on the distal small intestine.
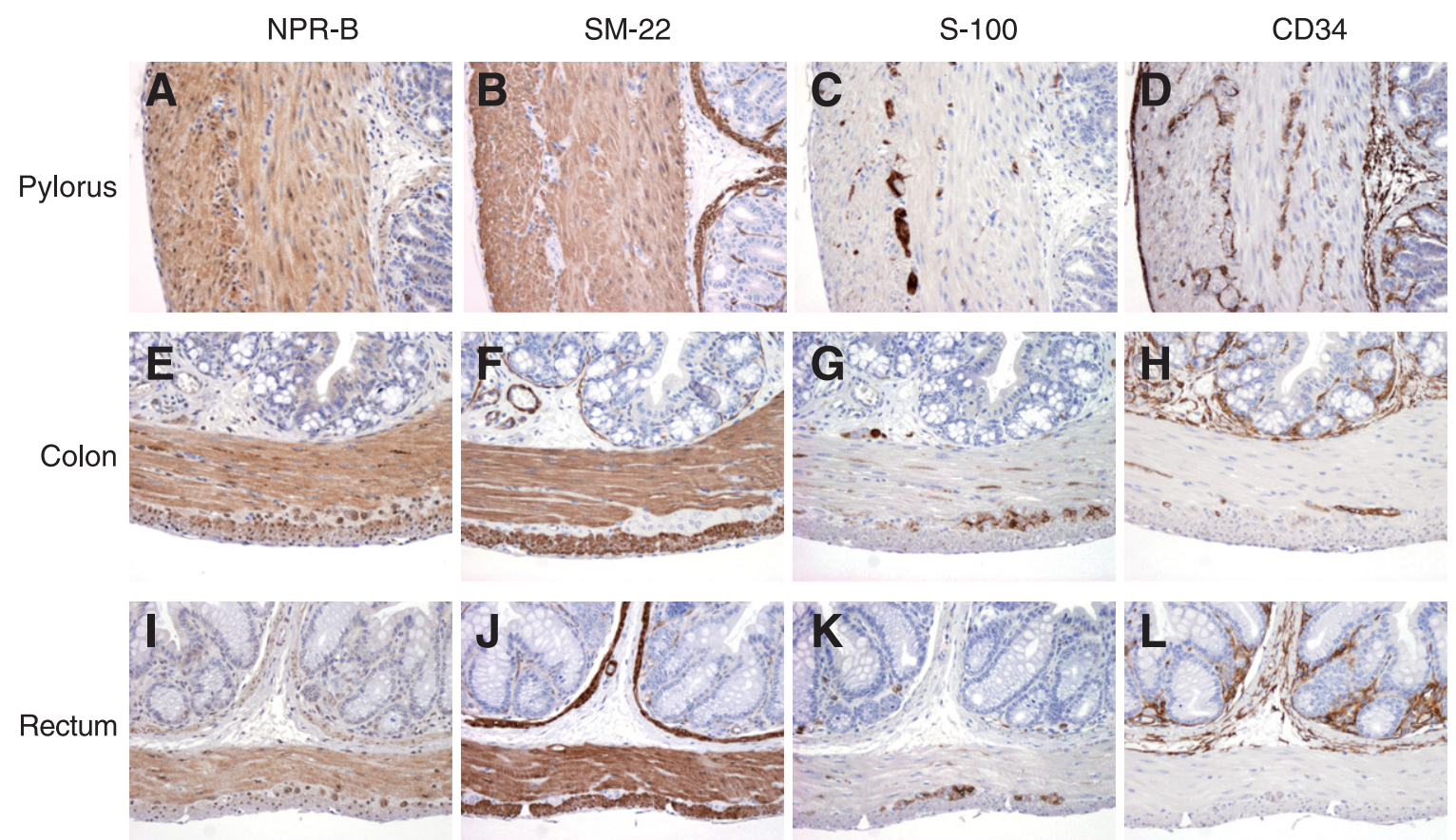

Figure 5 Immunolocalization of NPR-B in the pylorus, colon, and rectum, highly expressing NPR-B. Smooth muscle cells, Schwann cells, and small vessel endothelial cells were identified by immunostaining for SM22- $\alpha$ (B, F, and J), S-100 (C, G, and K), and CD34 (D, H, and L), respectively. NPR-B (A, E, and I) was localized to nerve fibers and to the nuclei and cytoplasm of smooth muscle cells but was not detected in Schwann cells or endothelial cells. Original magnification, object lens $\times 20$. 
In the present study, to clarify whether NPR-B is involved in an increase in cGMP levels induced by CNP administration in vivo, we first investigated the GI regions responsive to CNP as evidenced by cGMP production. The pylorus, colon, and rectum showed remarkable responses to CNP. However, cGMP levels were elevated in the pylorus, colon, and rectum immediately after CNP administration and then gradually decreased over time (Figure 1, C, G, and H). This suggested that the inhibition of pyloric and colorectal motility because of CNP-mediated smooth muscle relaxation is transient and that motility might be reactivated. In contrast, CNP probably has little influence on small intestinal motility, because the increase and decrease in cGMP were not significant. Furthermore, CNP-induced cGMP production was not observed in the GI tract in NPR-B-deficient $s l w / s l w$ mice (Figure 2A), indicating the NPR-B specificity of CNP action on GI tract.

We next investigated the effect of transient cGMP elevation induced by CNP administration on gastric emptying and intestinal transit. This effect may have been because of the reactivation of transient GI motility cessation in response to cGMP elevation. Although the CNP-induced cGMP elevation was transient, the effect on gastric emptying was only observed at 3 hours after CNP administration (Figure 3). This may be because, once the transient GI motility cessation occurred, the subsequent effect of reactivation persisted in the intestine. In this study, we investigated the effect of intravenous CNP injection on GI transit. Further studies are required to show the relation between intraperitoneal or oral administration of CNP and GI transit.

We subsequently investigated NPR-B expression and localization in GI tissues. Previous studies that used immunohistochemical staining with anti-CNP antibody and autoradiography with ${ }^{125} \mathrm{I}-\left[\mathrm{Tyr}^{0}\right]-\mathrm{CNP}-22$ showed that CNP and NPR-B localized to the cytoplasm of Schwann cells ${ }^{16}$ and smooth muscle cells. ${ }^{13,15}$ There have, however, been no detailed studies on NPR-B localization. Our results suggested that CNP specifically regulates the nervous system and muscle tension, causing relaxation and hyperpolarization of the pylorus and large intestine. cGMP was previously shown to act on membrane-bound calcium channels that regulate $\mathrm{Ca}^{2+}$ exchange across the cell membrane, acting as a neurotransmitter in the vascular system. ${ }^{19,20}$ Therefore, we speculate that CNP signaling has a similar effect on the GI tract.

We have previously described the lack of a response to CNP in the pylorus and large intestine of $s l w / s l w$ mice in a pharmacologic response study that used GI strips ${ }^{18}$ which is in agreement with the present in vivo results. These $s l w / s l w$ mice developed ileus or pyloric stenosis. The intestinal distension in $s l w / s l w$ mice was considered to be a gastric emptying and defecation disorder because of a CNP signaling deficiency. Thus, the $s l w / s l w$ mouse model is a strong aid in understanding the effect of cGMP production on NPR-B-mediated CNP signaling in the GI tract and in the pylorus, ileocecal and rectal region, and anus. Moreover, a recent study showed that a treatment with cGMP analogs via trans-membrane guanylyl cyclase reduced the rate of cell proliferation of intestinal cancer cells in vitro. ${ }^{21} \mathrm{We}$ therefore consider that CNP plays a pivotal role in GI motility/transit, in the repair mechanisms of intestinal epithelium, and in antitumor activity.

Our in vivo findings showed that NPR-B-mediated cGMP production stimulated by CNP administration contributes to gastric emptying. Future clinical trials that use CNP may enable an improved understanding of the role of CNP/NPR-B signaling in GI motility and may contribute to the development of novel therapeutics aimed at GI motility/ transit disorders, such as ileus and pyloric stenosis.

\section{Acknowledgments}

We thank Editage for providing editorial assistance, Mitsuru Koizumi along with all of the members in our program and Chisato Yoshida-Iwabuchi (Tokyo Medical and Dental University, Japan) for valuable discussions and suggestions, Hitomi Sudo (Molecular Imaging Center, National Institute of Radiological Sciences) for the negative control IgG and anti-actin antibody, Yasuhiro Fujiwara (Graduate School of Natural Science and Technology, Okayama University, Japan) for critical reading, Yuji Nozaki (Research Department of the Experimental Animals Biotechnical Center, Japan SLC, Inc.) for advice on animal handling, and Tetsu Nishikawa (Center for Laboratory Animals and Animal Experiment, Kyoto Pharmaceutical University, Japan) for encouragement.

\section{Supplemental Data}

Supplemental material for this article can be found at $h t t p: / /$ dx.doi.org/10.1016/j.ajpath.2012.09.015.

\section{References}

1. de Bold AJ: Atrial natriuretic factor: a hormone produced by the heart. Science 1985, 230:767-770

2. Sudoh T, Kangawa K, Minamino N, Matsuo H: A new natriuretic peptide in porcine brain. Nature 1988, 332:78-81

3. Sudoh T, Minamino N, Kangawa K, Matsuo H: C-type natriuretic peptide (CNP): a new member of natriuretic peptide family identified in porcine brain. Biochemical and biophysical research communications. 1990, 168:863-870

4. Potter LR, Hunter T: Guanylyl cyclase-linked natriuretic peptide receptors: structure and regulation. J Biol Chem 2001, 276:6057-6060

5. Pyne NJ, Arshavsky V, Lochhead A: cGMP signal termination. Biochem Soc Trans 1996, 24:1019-1022

6. Koller KJ, Lowe DG, Bennett GL, Minamino N, Kangawa K, Matsuo H, Goeddel DV: Selective activation of the B natriuretic peptide receptor by C-type natriuretic peptide (CNP). Science 1991, 252:120-123

7. Koller KJ, Goeddel DV: Molecular biology of the natriuretic peptides and their receptors. Circulation 1992, 86:1081-1088

8. Kuhn M: Molecular physiology of natriuretic peptide signalling. Basic Res Cardiol 2004, 99:76-82 
9. Mukoyama M, Nakao K, Hosoda K, Suga S, Saito Y, Ogawa Y, Shirakami G, Jougasaki M, Obata K, Yasue H, Kambayashi Y, Inoue $\mathrm{K}$, Imura $\mathrm{H}$ : Brain natriuretic peptide as a novel cardiac hormone in humans. Evidence for an exquisite dual natriuretic peptide system, atrial natriuretic peptide and brain natriuretic peptide. J Clin Invest 1991, 87:1402-1412

10. Suga S, Nakao K, Itoh H, Komatsu Y, Ogawa Y, Hama N, Imura H: Endothelial production of C-type natriuretic peptide and its marked augmentation by transforming growth factor-beta. Possible existence of "vascular natriuretic peptide system". J Clin Invest 1992, 90:1145-1149

11. Chen HH, Burnett JC Jr: C-type natriuretic peptide: the endothelial component of the natriuretic peptide system. J Cardiovasc Pharmacol 1998, 32(Suppl 3):S22-S28

12. Komatsu Y, Itoh H, Suga S, Ogawa Y, Hama N, Kishimoto I, Nakagawa O, Igaki T, Doi K, Yoshimasa T, Nakao K: Regulation of endothelial production of C-type natriuretic peptide in coculture with vascular smooth muscle cells. Role of the vascular natriuretic peptide system in vascular growth inhibition. Circ Res 1996, 78:606-614

13. Kim JH, Jeon GJ, Kim SZ, Cho KW, Kim SH: C-type natriuretic peptide system in rabbit colon. Peptides 2001, 22:2061-2068

14. Guo HS, Jin Z, Jin ZY, Li ZH, Cui YF, Wang ZY, Xu WX: Comparative study in the effect of C-type natriuretic peptide on gastric motility in various animals. World J Gastroenterol 2003, 9: $547-552$
15. Guo HS, Cui X, Cui YG, Kim SZ, Cho KW, Li ZL, Xu WX: Inhibitory effect of C-type natriuretic peptide on spontaneous contraction in gastric antral circular smooth muscle of rat. Acta Pharmacol Sin 2003, 24:1021-1026

16. Itaba S, Chijiiwa $\mathrm{Y}$, Matsuzaka H, Motomura Y, Nawata H: Presence of C-type natriuretic peptide (CNP) in guinea pig caecum: role and mechanisms of CNP in circular smooth muscle relaxation. Neurogastroenterol Motil 2004, 16:375-382

17. Sogawa C, Tsuji T, Shinkai Y, Katayama K, Kunieda T: Short-limbed dwarfism: slw is a new allele of Npr2 causing chondrodysplasia. J Hered 2007, 98:575-580

18. Sogawa C, Abe A, Tsuji T, Koizumi M, Saga T, Kunieda T: Gastrointestinal tract disorder in natriuretic peptide receptor B gene mutant mice. Am J Pathol 2010, 177:822-828

19. Ruiz-Velasco V, Zhong J, Hume JR, Keef KD: Modulation of Ca2+ channels by cyclic nucleotide cross activation of opposing protein kinases in rabbit portal vein. Circ Res 1998, 82:557-565

20. Herring N, Zaman JA, Paterson DJ: Natriuretic peptides like NO facilitate cardiac vagal neurotransmission and bradycardia via a cGMP pathway. Am J Physiol Heart Circ Physiol 2001, 281: $\mathrm{H} 2318-\mathrm{H} 2327$

21. Steinbrecher KA, Cohen MB: Transmembrane guanylate cyclase in intestinal pathophysiology. Curr Opin Gastroenterol 2011, 27: $139-145$ 